\title{
Memory consolidation in both trace and delay fear conditioning is disrupted by intra-amygdala infusion of the protein synthesis inhibitor anisomycin
}

\author{
Janine L. Kwapis, Timothy J. Jarome, Janet C. Schiff, and Fred J. Helmstetter ${ }^{1}$ \\ Department of Psychology, University of Wisconsin-Milwaukee, Milwaukee, Wisconsin 53211, USA
}

\begin{abstract}
Memory for delay fear conditioning requires the synthesis of new mRNA and protein in the basolateral amygdala. It is currently unknown whether similar molecular processes in the amygdala are required for the formation of trace fear memory, in which a stimulus-free interval is inserted between the conditional stimulus (CS) and unconditional stimulus (UCS). Here, we show that infusion of the protein synthesis inhibitor anisomycin into the basolateral amygdala disrupts consolidation of both trace and delay fear conditioning. This is the first evidence that protein synthesis in the amygdala is necessary for the formation of both trace and delay fear memory.
\end{abstract}

[Supplemental material is available for this article.]

Pavlovian fear conditioning has been widely used to identify the neural substrates of memory. In fear conditioning, an animal learns to associate an initially neutral conditional stimulus (CS) with an aversive unconditional stimulus (UCS). In the standard version of this task, termed "delay" fear conditioning, the CS and UCS are presented in a temporally contiguous manner. Numerous studies have shown that the amygdala plays a central role in associating the CS and UCS during delay fear acquisition (Fanselow and LeDoux 1999; Maren 2001; Helmstetter et al. 2008). The formation of stable long-term memory in delay conditioning can be disrupted by inhibiting either mRNA or protein synthesis in the amygdala immediately before or after training (Bailey et al. 1999; Parsons et al. 2006a,b).

In trace fear conditioning (TFC), the CS and UCS are separated by an empty trace interval (TI) of several seconds. Importantly, the temporal separation of these two stimuli dramatically alters the neural mechanisms underlying acquisition and consolidation of this memory. Whereas delay fear conditioning is thought to rely primarily on the amygdala, additional structures such as the hippocampus and medial prefrontal cortex (mPFC) are critical for learning in TFC (e.g., McEchron et al. 1998; Quinn et al. 2002; Gilmartin and McEchron 2005; Gilmartin and Helmstetter 2010). Disrupting plasticity in either the mPFC or dorsal hippocampus with ERK inhibitors or NMDA receptor antagonists can disrupt learning the CS-UCS association in TFC (Runyan et al. 2004; Quinn et al. 2005; Gilmartin and Helmstetter 2010). The hippocampus also plays a key role in the association of the training context with the UCS in both delay and trace fear conditioning (Kim and Fanselow 1992; Quinn et al. 2002).

Most of the research on TFC has focused on the MPFC and hippocampus, largely ignoring the contribution of the amygdala. Because the amygdala seems to play a very clear role in delay fear conditioning, it has been widely assumed to play a similar role in TFC (Selden et al. 1991). It is possible, however, that the amygdala is not required for TFC memory formation. Consistent with this idea, recent research has indicated that neural activity in the amygdala may not be required. Specifically, Raybuck and Lattal

\footnotetext{
1'Corresponding author.

E-mail fjh@uwm.edu.

Article is online at http://www.learnmem.org/cgi/doi/10.1101/Im.023945.111.
}

(2011) reported that inactivation of amygdala neurons was sufficient to disrupt delay, but not trace fear acquisition. Therefore, it is currently unclear whether the amygdala plays any role in TFC acquisition or consolidation.

The purpose of this study was to determine whether the amygdala is required for TFC memory consolidation. To this end, we injected the protein synthesis inhibitor anisomycin into the amygdala immediately after trace or delay conditioning. If the amygdala is critical for both types of conditioning, one would expect anisomycin to disrupt both delay and trace fear consolidation similarly. If the amygdala is not a crucial structure in the trace fear conditioning circuit, however, anisomycin infusion into the amygdala should not disrupt trace fear memory.

The subjects were 39 male Long-Evans rats (300-375 g; Harlan, Madison, WI) housed individually with free access to water and rat chow. The colony room was maintained under a 14:10-h light-dark cycle, and all behavioral tests were conducted during the light portion of this cycle. All procedures were approved by the Institutional Animal Care and Use Committee and were in accordance with the NIH Guidelines for the Care and Use of Experimental Animals.

All animals were anesthetized with $2 \%-4 \%$ isoflurane in $100 \% \mathrm{O}_{2}$ and implanted with bilateral stainless steel 26-gauge cannulae aimed at the basolateral nucleus of the amygdala (BLA) using stereotaxic coordinates (AP $-2.9 \mathrm{~mm}, \mathrm{ML} \pm 5.0 \mathrm{~mm}, \mathrm{DV}$ $-7.2 \mathrm{~mm}$ ) relative to bregma. Cannulae were secured to the skull with stainless steel screws, superglue, and dental acrylic. Rats were given a recovery period of at least $7 \mathrm{~d}$ before behavioral testing.

Fear conditioning acquisition was conducted in a set of four identical chambers (Context A). The floor of Context A was composed of stainless steel rods through which footshocks were delivered. Each chamber was illuminated by an overhead $7.5 \mathrm{~W}$ bulb and cleaned with a solution of $5 \%$ ammonium hydroxide. A second set of chambers (Context B) was used to measure freezing to the auditory CS independent of the training context. Context B had a number of distinct features, including infrared illumination, a solid and opaque textured floor panel, and a different cleaning solution ( $5 \%$ acetic acid).

Three sets of training parameters were used (Fig. 1A). For all conditions, a 10 -sec white noise CS $(72 \mathrm{~dB})$ was paired with a 

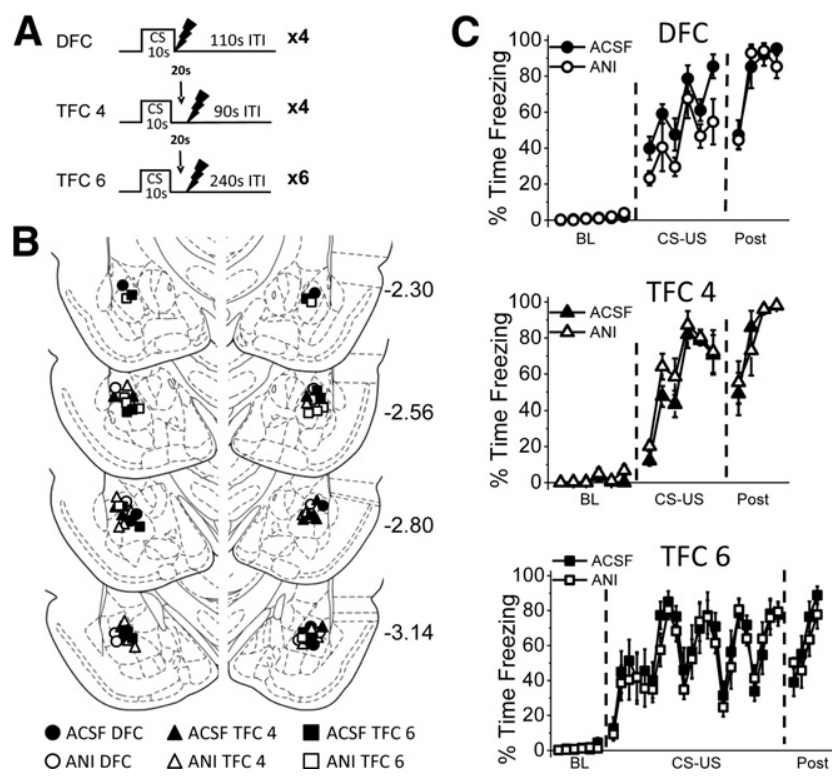

Figure 1. Animals show normal acquisition of DFC, TFC 4, and TFC 6 training before drug infusion. $(A)$ The training protocol. Animals were trained with four pairings of delay fear conditioning (DFC), four pairings of trace fear conditioning (TFC 4), or six pairings of trace fear conditioning (TFC 6). (B) Locations of infusion sites for animals infused with either ACSF (black symbols) or ANI (white symbols) and trained with DFC (circles), TFC 4 (triangles), or TFC 6 (squares). (Diagrams are adapted from Paxinos and Watson [1998] and reprinted with permission from Elsevier (C) 1998.) (C) Mean percent time freezing during each minute of acquisition of DFC (top), TFC 4 (middle), or TFC 6 (bottom). Animals show similar acquisition curves during the baseline (BL), CS-US association (CS-US), and post-shock (post) periods.

1-sec UCS footshock (1.0 mA). Animals assigned to the delay fear conditioning (DFC) group $(n=15)$ were given four pairings of delay conditioning after a 6-min baseline period. For DFC animals, the UCS was delivered at the moment of UCS offset, and a variable intertrial interval (ITI) of $110 \mathrm{sec} \pm 20 \mathrm{sec}$ separated the four CS-UCS pairings. Animals assigned to the four-trial trace fear conditioning (TFC 4$)$ group $(n=12)$ also received four pairings after a 6-min baseline period, except that the CS and UCS were temporally separated by an empty 20 -sec trace interval. Further, a variable ITI of $90 \mathrm{sec} \pm 20 \mathrm{sec}$ was used to make the TFC 4 conditioning session the same length as the DFC conditioning session. The TFC 4 parameters were chosen to parallel the number of trials and total session length of the DFC group to allow direct comparison of trace and delay conditioning. Finally, animals assigned to the six-trial trace fear conditioning (TFC 6) group $(n=12)$ received a total of six CS-UCS pairings in a slightly longer conditioning session designed to produce enhanced TFC acquisition. After the 6-min baseline period, TFC 6 animals received six trials of the CS and UCS separated by a 20 -sec TI. In order to produce maximal CS-UCS association in TFC 6 animals, the ITI was also lengthened to $240 \pm 20 \mathrm{sec}$, based on previous research demonstrating that increasing the time between conditioning trials will enhance learning of the CS-UCS relationship in trace conditioning (e.g., Detert et al. 2008). Animals were removed from the conditioning chambers four minutes after the final UCS.

All rats received bilateral infusions of $0.5 \mu \mathrm{L} /$ side into the BLA over a 60 -sec period immediately after training. Rats were either infused with the protein synthesis inhibitor anisomycin (ANI; $n=18$; DFC $n=7$; TFC $4 n=5$; TFC $6 n=6$ ) or with the vehicle (ACSF; $n=21$; DFC $n=8$; TFC $4 n=7$; TFC $6 n=6$ ). ANI was dissolved in $\mathrm{HCl}(\sim 90 \mu \mathrm{L})$ and diluted with artificial cerebrospinal fluid (ACSF) to the final concentration of $125 \mu \mathrm{g} /$ $\mu \mathrm{L}$. A small amount of $\mathrm{NaOH}(\sim 4 \mu \mathrm{L})$ was added to bring the $\mathrm{pH}$ to 7.4 to match the vehicle ACSF. Our preparation of anisomycin was identical to that used in previous anisomycin studies (Nader et al. 2000; Schafe and LeDoux 2000; Parsons et al. 2006a,b; Wilensky et al. 2006) and has reliably been shown to produce a reduction of $\sim 60 \%$ in protein synthesis without lesions (e.g., Parsons et al. 2006a). Normal retraining has been observed following ANI infusion in our lab (Parsons et al. 2006a) and others (e.g., Wilensky et al. 2006), demonstrating that ANI infusion does not produce significant amygdala damage. After each infusion, the injectors (33-gauge, cut to extend $0.5-0.7 \mathrm{~mm}$ beyond the guide cannulae) remained in place for an additional $90 \mathrm{sec}$ to ensure proper diffusion. Prior work with these parameters indicates they produce bilateral coverage throughout the amygdala (Parsons et al. 2006a,b).

Twenty-four hours after training, rats were given a context test in Context A counterbalanced with a CS retention test in Context B. For the context test, animals were returned to the conditioning chamber for $12 \mathrm{~min}$. The CS retention test consisted of a 1-min baseline period followed by eight discrete 30 -sec presentations of the CS (72 dB), with a 60-sec ITI. Discrete presentations of the CS allowed us to measure freezing behavior during both the CS and ITI periods of the test. The ITI serves as a measure of fear during the period immediately after the CS offset, making it comparable to the empty trace interval present during acquisition. The context and CS tests were presented $4 \mathrm{~h}$ apart, so that each animal received both a context and CS test on the same day.

Freezing was used to quantify conditional fear during all training and testing sessions. Freezing behavior was scored in real time using a digital video observation system (FreezeScan 1.0, Clever Sys Inc.) that continuously scored each rat as freezing or active. Freezing was analyzed as the amount of freezing per minute (baseline periods, training sessions, and context sessions), freezing during the CS presentations (30- sec period during test CS presentations), or freezing during the ITI (60-sec period between test CS presentations). Statistical analysis of freezing during the CS test was conducted using the average of the first three trials, as this best represents the response to the CS before extinction begins to occur (see Supplemental Fig. S1). This procedure is consistent with other studies using discrete CS presentations during the test session to test trace fear memory (e.g., Quinn et al. 2002, 2005; Yoon and Otto 2007). Behavioral data were analyzed using two-way ANOVAs (factors: training type and drug) and Student's $t$-tests (to test the drug effects within each type of training). In all analyses, an $\alpha$ value of 0.05 was required for significance.

After behavioral testing was complete, animals were killed with an overdose of isoflurane and transcardially perfused. For detailed procedures, see Kwapis et al. (2009). Briefly, after fixation, brains were removed, cryoprotected, sectioned, and stained with cresyl violet to verify cannulae placements. Four rats were excluded from analysis due to misplaced cannulae. The cannulae placements for the remaining 39 animals were deemed acceptable and were included in subsequent analyses (Fig. 1B).

All animals showed normal acquisition using DFC, TFC 4, or TFC 6 conditioning protocols (Fig. 1C) before drug infusion. Low freezing during the baseline period indicated that animals did not respond to the training context prior to the CS-UCS pairings. Further, there was no significant difference between groups in the amount of freezing during the 4-min period after the final stimulus presentation for DFC animals $\left(t_{(13)}=0.098, P=0.923\right)$, TFC 4 animals $\left(t_{(10)}=0.197, P=0.848\right)$, or TFC 6 animals $\left(t_{(10)}=0.472 ; P=0.647\right)$. These data indicate that animals within each training condition showed equivalent freezing levels prior to drug infusion. 
Immediately after training, animals were infused with ANI or ACSF into the BLA and were tested the following day to the context and CS (Fig. 2A). Extinction appeared to begin after the third trial for all three training conditions (Supplemental Fig. S1A,B). Therefore, we focused on the average of the first three CS presentations and the corresponding ITI periods in statistical analyses. Infusion of ANI into the BLA disrupted freezing behavior during both the CS test (Fig. 2B,C) and the context test (Fig. 2D) for all groups. During the CS presentation (Fig. 2B), we observed a significant main effect for $\operatorname{drug}\left(F_{(1,33)}=16.773, P<0.001\right)$ but no significant main effect for type of training $\left(F_{(2,33)}=1.311, P=0.283\right)$ and no significant Training $\times$ Drug interaction $\left(F_{(2,33)}=0.320\right.$, $P=0.728)$. The lack of a significant interaction demonstrates that we were unable to detect any differential effects for ANI among the three types of training. Student's $t$-tests comparing drug conditions within each training group demonstrated that ANI significantly impaired freezing for DFC animals $\left(t_{(13)}=\right.$ $2.769, P=0.016$ ). While TFC 4 animals given ANI also showed reduced CS freezing, they were not significantly impaired relative to control animals $\left(t_{(10)}=1.984, P=0.075\right)$. The lack of a significant drug effect in TFC 4 animals was likely due to the relatively low levels of freezing in the vehicle animals, as freezing in the ANI group was already at minimal levels $(M=2.52 \%)$. Thus,
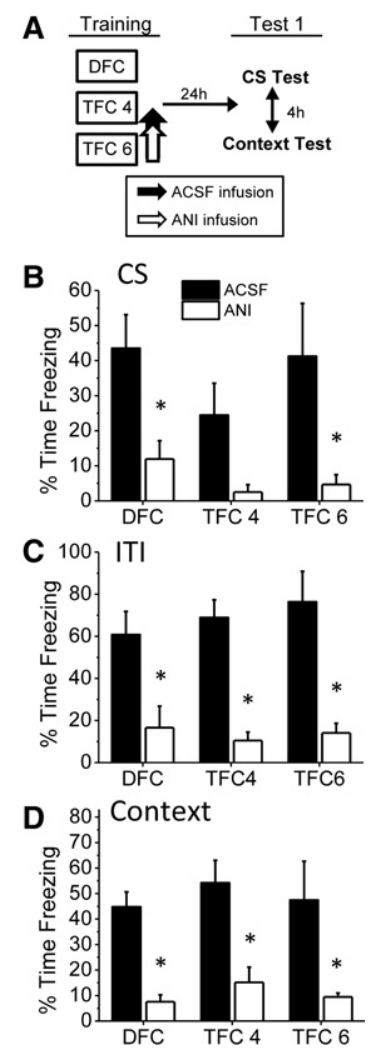

Figure 2. Both delay and trace fear consolidation are disrupted by intraBLA infusion of anisomycin. (A) The experimental timeline. Animals received ANI $(125 \mu \mathrm{g} / \mu \mathrm{L} ; 0.5 \mu \mathrm{L} /$ side $)$ or ACSF infusions immediately after DFC, TFC 4, or TFC 6 training and were tested the following day. $(B)$ Mean percent time freezing during the CS presentations. DFC and TFC 6 animals given ANI froze significantly less than ACSF controls. TFC 4 animals showed a nonsignificant reduction in freezing. (C) Mean percent time freezing during the ITI periods of the CS test. DFC, TFC 4, and TFC 6 animals given ANI all show significantly attenuated freezing relative to vehicle animals. $(D)$ Mean percent time freezing during the context test. DFC, TFC 4, and TFC 6 animals all show significantly reduced freezing after ANI infusion. $\left(^{*}\right) P \leq 0.05$ relative to vehicle. weak learning in the vehicle TFC 4 animals did not produce sufficient freezing to detect an impairment. Consistent with this explanation, significantly reduced freezing was observed in ANI for TFC 6 training, in which stronger trace conditioning parameters were used $\left(t_{(10)}=2.388, P=0.038\right)$. These results demonstrate that CS freezing for both trace and delay conditioning is disrupted by infusion of ANI into the BLA immediately after acquisition.

A similar pattern was observed during the testing ITI periods (Fig. 2C). ITI freezing is commonly used to measure learning of TFC, as it represents CS-induced fear to the trace interval and encompasses the time at which the TFC-trained animal would have received the footshock during training (see Quinn 2002, 2005; Blum et al. 2006; Yoon and Otto 2007; Detert et al. 2008). An ANOVA performed on ITI freezing during the CS test illustrated a main effect for drug $\left(F_{(1,33)}=44.591, P<0.001\right)$ but no main effect for training type $\left(F_{(2,33)}=0.243, P=0.785\right)$ and no significant Training $\times$ Drug interaction $\left(F_{(2,33)}=0.481, P=0.623\right)$. Individual $t$-tests illustrated that ANI significantly impaired freezing for DFC animals $\left(t_{(13)}=2.918, P=0.012\right)$, TFC 4 animals $\left(t_{(10)}=4.104, P=0.002\right)$, and TFC 6 animals $\left(t_{(10)}=4.013, P=\right.$ $0.002)$ relative to vehicle controls. As with CS freezing, these results indicate that intra-BLA ANI disrupted consolidation of both TFC and DFC.

Context freezing was also disrupted by post-training ANI infusions into the BLA (Fig. 2D; Supplemental Fig. S1C). A significant effect of drug was observed $\left(F_{(1,33)}=34.429, P<0.001\right)$, but no effect for training $\left(F_{(2,33)}=0.610, P=0.550\right)$ or Training $\times$ Drug interaction $\left(F_{(2,33)}=0.007, P=0.993\right)$ was present. Again, individual $t$-tests revealed a significant effect for drug within each of the three types of training (DFC: $t_{(13)}=5.468, P<0.001$; TFC 4: $t_{(10)}=3.333, P=0.008$; TFC 6: $t_{(10)}=2.487, P=0.032$ ). This demonstrates that context fear formed during both trace and delay conditioning was also disrupted by anisomycin infusion into the BLA.

To summarize, our results demonstrate that intra-BLA infusions of the protein synthesis inhibitor anisomycin disrupt consolidation to both the discrete CS and to the context following either four or six pairings of trace fear conditioning. We have also replicated the finding that anisomycin infusions into the BLA disrupt CS and context consolidation following delay fear conditioning. Thus, preventing protein synthesis with ANI in the BLA disrupted trace fear consolidation in the same way that it disrupts delay fear consolidation. This is the first evidence that the BLA is crucial for the consolidation of both trace and delay fear conditioning.

Our conclusion that plasticity in the amygdala is required for trace fear consolidation generally conflicts with the findings of Raybuck and Lattal (2011), who showed that inactivation of the amygdala with muscimol did not impair trace fear acquisition. There are a number of possible reasons for this contradiction. First, there were numerous procedural differences between the two studies. For example, the current study used rats rather than mice. Similarly, we used four or six trials of trace conditioning, whereas Raybuck and Lattal used four or fewer pairings in a shorter training session. It is possible that these procedural differences produced qualitatively different forms of learning with unique neural requirements. This explanation seems unlikely, however, because animals trained in both paradigms were able to express substantial freezing behavior to the CS during testing. A second possibility is that plasticity (as reflected by the requirement for macromolecular synthesis) but not neural activity in the amygdala is required for trace fear conditioning. It is feasible that inactivation of the amygdala with muscimol does not fully impair intracellular plasticity, which may continue to occur as a result of afferent stimulation from distal inputs to the amygdala. 
Consistent with this logic, past studies have demonstrated that protein synthesis and memory reconsolidation can occur normally despite inactivation of the amygdala with the AMPA receptor antagonist CNQX (Ben Mamou et al. 2006). Thus, despite muscimol-induced hyperpolarization of amygdalar cells, plasticity might still occur to support trace fear acquisition. A final possibility is that compensatory mechanisms can support trace fear learning when amygdala neurons are inactivated during the acquisition or consolidation periods. It is conceivable that other structures could support the trace association in the absence of amygdala activity, given the network of areas that participate in trace fear, including both cortical regions and the hippocampus. Indeed, other forms of hippocampus-dependent learning, such as context fear conditioning, can be acquired though alternate mechanisms if the hippocampus is inactivated prior to training (e.g., Rudy and O'Reilly 1999; Wiltgen et al. 2006). From this perspective, inactivation of amygdala neurons during trace fear conditioning may have triggered the activation of supporting structures, whereas protein synthesis inhibition used in the present study was insufficient to access these compensatory mechanisms. In any case, our results clearly demonstrate that infusion of anisomycin into the amygdala disrupts both trace and delay fear consolidation.

Interestingly, we observed slightly higher levels of freezing during the ITI than during the CS presentation for both trace and delay animals (Fig. 2C). The most likely explanation is that the animals began freezing during the discrete CS and simply continued that behavioral suppression through the empty interval after CS offset. Animals generally oriented to the CS onset for a few seconds each trial; this orienting behavior was not present following the CS offset, resulting in higher mean freezing during the ITI. All animals showed adequate evidence of learning the predictive relationship between the CS and UCS, as demonstrated by increased freezing to the CS after the baseline period. One alternative possibility is that freezing during the ITI represents generalized freezing to the novel context, rather than fear to the CS itself. This is unlikely because baseline freezing for both drug groups in all three training conditions was minimal, suggesting that the animals do not generalize fear to the novel context. Further, ANI-induced deficits were only observed following the CS presentation; in no instance was the anisomycin group impaired during baseline freezing, because vehicle animals did not freeze at meaningful levels until the CS onset. This supports the contention that anisomycin specifically disrupted CS-induced freezing, rather than some disruption of generalized context fear.

One potential criticism of our study is that anisomycin is considered a "dirty" drug with a number of unintended effects, like inhibiting catecholamine synthesis (e.g., Flexner and Goodman 1975), inducing gene expression (see Radulovic and Tronson 2008), or producing cell death (Iordanov et al 1997, 1998; Rudy 2008). This makes it difficult to conclude with absolute certainty that the effects we observed were from specific inhibition of translation, rather than one of these side effects. Regardless of how anisomycin is acting, it is obvious that application of this drug into the BLA has the same effect on trace and delay fear, indicating that the BLA is playing a similar role in each. Additionally, it is possible that our targeted infusion of ANI into the BLA disrupted protein synthesis in brain regions other than the amygdala, such as the hippocampus. Although others have observed decreases in protein synthesis in brain regions outside of the targeted structure after ANI infusion (Maren et al. 2003), prior work in our lab has demonstrated the effectiveness of this dose and volume in disrupting protein synthesis bilaterally throughout the BLA (Parsons et al. 2006a,b). Further, Maren and colleagues (2003) have demonstrated that the same volume and concentration of ANI infused into the BLA does not disrupt protein synthesis in the dorsal hippocampus. It is, therefore, unlikely that our observed disruption of trace fear memory is because ANI is disrupting hippocampal, rather than amygdalar, tissue. Despite the focal nature of our infusion, we cannot entirely rule out the possibility that anisomycin diffused into adjacent structures that play a key role in trace fear, such as the entorhinal and perirhinal cortices (KholodarSmith et al. 2008; Esclassan et al. 2009).

One final possibility is that the amygdala, while important for trace fear consolidation, does not play the exact same role in trace and delay fear. Our results demonstrate that anisomycin infusion into the amygdala disrupts both types of fear memory; however, it is unclear whether the amygdala continues to store the memory after consolidation for trace fear conditioning as with delay (Lee et al. 1996; Maren et al. 1996; Fanselow and Gale 2003) or whether the BLA is important for the extinction or reactivation of trace fear memory, as with delay fear (e.g., Falls et al. 1992; Nader et al. 2000; Herry et al. 2006). These important questions should be addressed in future studies.

In conclusion, we have shown for the first time that infusion of anisomycin into the BLA can disrupt not only delay, but also trace fear conditioning. Thus, consolidation of trace fear conditioning, like delay fear conditioning, appears to require new protein synthesis in the BLA.

\section{Acknowledgments}

This research was supported by the National Institute of Mental Health (NIMH) grants MH069558 and MH09426 to F.J.H. and MH090685 to J.L.K. We thank Marieke Gilmartin and Mary Lonergan for technical assistance.

\section{References}

Bailey DJ, Kim JJ, Sun W, Thompson RF, Helmstetter FJ. 1999. Acquisition of fear conditioning in rats requires the synthesis of mRNA in the amygdala. Behav Neurosci 113: 276-282.

Ben Mamou C, Gamache K, Nader K. 2006. NMDA receptors are critical for unleashing consolidated auditory fear memories. Nat Neurosci 9: 1237-1239.

Blum S, Hebert AE, Dash PK. 2006. A role for the prefrontal cortex in recall of recent and remote memories. Neuroreport 17: 341-344.

Detert JA, Kampa ND, Moyer JR Jr. 2008. Differential effects of training intertrial interval on acquisition of trace and long-delay fear conditioning in rats. Behav Neurosci 122: 1318-1327.

Esclassan F, Coutureau E, Di Scala G, Marchand AR. 2009. A cholinergicdependent role for the entorhinal cortex in trace fear conditioning. J Neurosci 29: 8087-8093.

Falls WA, Miserendino MJD, Davis M. 1992. Extinction of fear-potentiated startle: Blockade by infusion of an NMDA antagonist into the amygdala. J Neurosci 12: 854-863.

Fanselow MS, Gale GD. 2003. The amygdala, fear, and memory. Ann NY Acad Sci 985: 125-134

Fanselow MS, LeDoux JE. 1999. Why we think plasticity underlying Pavlovian fear conditioning occurs in the basolateral amygdala. Neuron 23: $229-232$

Flexner LB, Goodman RH. 1975. Studies on memory: Inhibitors of protein synthesis also inhibit catecholamine synthesis. Proc Natl Acad Sci 72: 4660-4663.

Gilmartin MR, Helmstetter FJ. 2010. Trace and contextual fear conditioning require neural activity and NMDA receptor-dependent translation in the medial prefrontal cortex. Learn Mem 17: 289-296.

Gilmartin MR, McEchron MD. 2005. Single neurons in the dentate gyrus and CA1 of the hippocampus exhibit inverse patterns of encoding during trace fear conditioning. Behav Neurosci 119: 164-179.

Helmstetter FJ, Parsons RG, Gafford GM. 2008. Macromolecular synthesis, distributed plasticity, and fear conditioning. Neurobiol Learn Mem 89: $324-337$.

Herry C, Trifilieff P, Micheau J, Luthi A, Mons N. 2006. Extinction of auditory fear conditioning requires MAPK/ERK activation in the basolateral amygdala. Eur J Neurosci 24: 261-269.

Iordanov MS, Pribnow D, Magun JL, Dinh TH, Pearson JA, Chen SL, Magun BE. 1997. Ribotoxic stress response: Activation of the stressactivated protein kinase JNK1 by inhibitors of the peptidyl transferase 
reaction and by sequence-specific RNA damage to the $\alpha$-sarcin/ricin loop in the 28S rRNA. Mol Cell Biol 17: 3373-3381.

Iordanov MS, Pribnow D, Magun JL, Dinh TH, Pearson JA, Magun BE. 1998. Ultraviolet radiation triggers the ribotoxic stress response in mammalian cells. J Biol Chem 273: 15794-15803.

Kholodar-Smith DB, Boguszewski P, Brown TH. 2008. Auditory trace fear conditioning requires perirhinal cortex. Neurobiol Learn Mem 90: 537-543.

Kim JJ, Fanselow MS. 1992. Modality-specific retrograde amnesia of fear. Science 256: 675-677.

Kwapis JL, Jarome TJ, Lonergan ME, Helmstetter FJ. 2009. Protein kinase M maintains fear memory in the amygdala but not in the hippocampus. Behav Neurosci 123: 844-850.

Lee Y, Walker D, Davis M. 1996. Lack of a temporal gradient of retrograde amnesia following the fear-potentiated startle paradigm. Behav Neurosci 110: $836-839$.

Maren S. 2001. Neurobiology of Pavlovian fear conditioning. Аnnu Rev Neursoci 24: 897-931.

Maren S, Aharanov G, Fanselow MS. 1996. Retrograde abolition of conditional fear after excitotoxic lesions of the basolateral amygdala of rats: Absence of a temporal gradient. Behav Neurosci 110: 718-726.

Maren S, Ferrario CR, Corcoran KA, Desmond TJ, Frey KA. 2003. Protein synthesis in the amygdala, but not the auditory thalamus, is required for consolidation of Pavlovian fear conditioning in rats. Eur J Neurosci 18: $3080-3088$.

McEchron MD, Bouwmeester H, Tseng W, Weiss C, Disterhoft JF. 1998. Hippocampectomy disrupts auditory trace fear conditioning and contextual fear conditioning in the rat. Hippocampus 8: 638-646.

Nader K, Schafe GE, LeDoux JE. 2000. Fear memories require protein synthesis in the amygdala for reconsolidation after retrieval. Nature 406: $722-726$.

Parsons RG, Gafford GM, Baruch DE, Riedner BA, Helmstetter FJ. 2006a. Long-term stability of fear memory depends on the synthesis of protein but not mRNA in the amgydala. Eur J Neurosci 23: 1853-1859.

Parsons RG, Gafford GM, Helmstetter FJ. 2006b. Translational control via the mammalian target of rapamycin pathway is critical for the formation and stability of long-term fear memory in amygdala neurons. J Neurosci 26: 12977-12983.

Paxinos G, Watson C. 1998. The rat brain in stereotaxic coordinates. Academic Press, San Diego, CA.
Quinn JJ, Ommen SS, Morrison GE, Fanselow MS. 2002. Post-training excitotoxic lesions of the dorsal hippocampus attenuate forward trace, backward trace, and delay fear conditioning in a temporally specific manner. Hippocampus 12: 495-504.

Quinn JJ, Loya F, Ma QD, Fanselow MS. 2005. Dorsal hippocampus NMDA receptors differentially mediate trace and contextual fear conditioning. Hippocampus 15: 665-674.

Radulovic J, Tronson NC. 2008. Protein synthesis inhibitors, gene superinduction, and memory: Too little or too much protein? Neurobiol Learn Mem 89: 212-218.

Raybuck JD, Lattal KM. 2011. Double dissociation of amygdala and hippocampal contributions to trace and delay fear conditioning. Plos One 6: pe15982. doi: 10.1371/journal.pone.0015982.

Rudy JW. 2008. Is there a baby in the bathwater? Maybe: Some methodological issues for the de novo protein synthesis hypothesis. Neurobiol Learn Mem 89: 219-224.

Rudy JW, O'Reilly RC. 1999. Contextual fear conditioning, conjunctive representations, pattern completion, and the hippocampus. Behav Neurosci 113: 867-880.

Runyan JD, Moore AN, Dash PK. 2004. A role for prefrontal cortex in memory storage for trace fear conditioning. J Neurosci 24: 1288-1295.

Schafe GE, LeDoux JE. 2000. Memory consolidation of auditory Pavlovian fear conditioning requires protein synthesis and protein kinase $\mathrm{A}$ in the amygdala. J Neurosci 20: RC961-RC965.

Selden NRW, Everitt BJ, Jarrard LE, Robbins TW. 1991. Complementary roles for the amygdala and hippocampus in aversive conditioning to explicit and contextual cues. Neuroscience 42: 335-350.

Wilensky AE, Schafe GE, Kristensen MP, LeDoux JE. 2006. Rethinking the fear circuit: The central nucleus of the amygdala is required for the acquisition, consolidation, and expression of Pavlovian fear conditioning. J Neurosci 26: 12387-12396.

Wiltgen BJ, Sanders MJ, Anagnostaras SG, Sage JR, Fanselow MS. 2006. Context fear learning in the absence of the hippocampus. J Neurosci 26: $5484-5491$.

Yoon T, Otto T. 2007. Differential contributions of dorsal vs. ventral hippocampus to auditory trace fear conditioning. Neurobiol Learn Mem 87: $464-475$.

Received August 14, 2011; accepted in revised form September 22, 2011. 


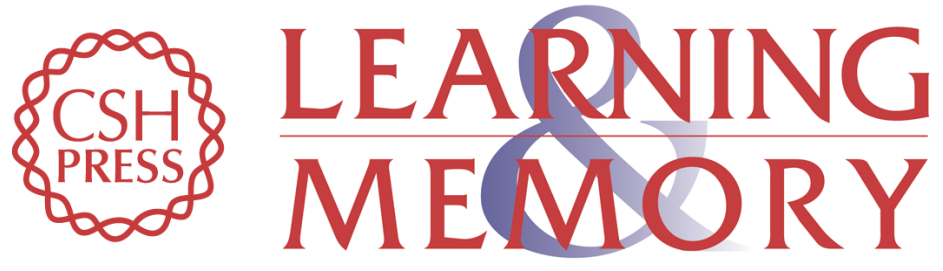

\section{Memory consolidation in both trace and delay fear conditioning is disrupted by intra-amygdala infusion of the protein synthesis inhibitor anisomycin}

Janine L. Kwapis, Timothy J. Jarome, Janet C. Schiff, et al.

Learn. Mem. 2011, 18:

Access the most recent version at doi:10.1101//m.023945.111

Supplemental http://learnmem.cshlp.org/content/suppl/2011/10/25/18.11.728.DC1

Material

References This article cites 38 articles, 11 of which can be accessed free at: http://learnmem.cshlp.org/content/18/11/728.full.html\#ref-list-1

License

Email Alerting Receive free email alerts when new articles cite this article - sign up in the box at the Service top right corner of the article or click here. 